Académicos vietnamitas analizan el desarrollo de la teoría de la empresarialidad destacando las contribuciones "austriacas"

\author{
Martin Krause \\ 6 enero, 2020 \\ El foro y el bazar
}

Universidad Francisco Marroquín

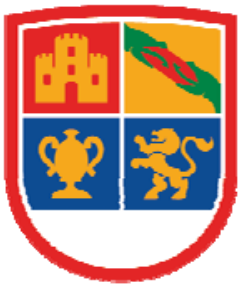

UFM

UNIVERSIDAD

FRANCISCO

MARROQUIN

VERITAS - LIBERTAS - JVSTITIA

https://bazar.ufm.edu/academicos-vietnamitas-analizan-desarrollo-la-teoria-la-empresarialidaddestacando-las-contribuciones-austriacas/ 


\title{
Académicos vietnamitas analizan el desarrollo de la teoría de la empresarialidad destacando las contribuciones «austriacas»
}

\author{
Posted on 6 enero, 2020 por Martin Krause
}

Impresionante. En el otro lado del mundo, en un país que fue comunista durante un par de décadas y que aun pretende serlo, aunque su economía sea más abierta y de mercado que la argentina, sus académicos también parecen tener más claro dónde buscar teorías económicas para entender el fenómeno empresarial que allí ocurre.

Así, por ejemplo, este paper: What have Vietnamese scholars learned from researching entrepreneurship?: A systematic review

Quan-Hoang Vuong; Viet-Phuong La; Manh-Toan Ho; Thu-Trang Vuong; Phuong-Hanh Hoang

Working Paper No. PKA-1902; Centre for Interdisciplinary Social Research; Phenikaa University.

\section{https://works.bepress.com/quan-hoang-vuong/248/}

Se preguntan qué aprendieron los académicos vietnamitas sobre la empresarialidad, y parece que han acertado en buscar las fuentes. Revisando las referencias se trata de autores con una prolífica actividad de investigación y publicaciones. En una parte del paper, dicen:

\footnotetext{
"A pesar de la presencia ubicua en la vida cotidiana, el espíritu empresarial sigue siendo un «Forastero» en la teoría económica dominante. Al principio, Adam Smith descartó el papel de los empresarios en su análisis y la exclusión ha continuado a lo largo de la formulación de las ciencias económicas (Landstrom, 2010). En ciencias económicas mainstream, el uso de las matemáticas y el desarrollo de modelos matemáticos son prácticas comunes. Sin embargo, la notable contribución a la teoría del emprendimiento fue desarrollado por académicos de la escuela de economía austriaca, quienes fueron conocidos por su aversión por el uso de modelos matemáticos (Yeager, 1997). Por lo tanto, los estudios de «emprendimiento» fueron dispersos y solo hasta el siglo XIX surgieron algunos análisis significativos. Carl Menger fue
} 
uno de los primeros en estudiar la empresarialidad y definió al emprendedor: los emprendedores son aquellos que crean, calculan y gestionan actividades productivas (Campagnolo y Vivel, 2014). Más tarde, los estudiosos de la economía austriaca como Eugen Bohm von Bawerk, Friedrich von Wieser y Joseph Schumpeter - continuaron desarrollando la empresarialidad desde la perspectiva del individuo y elevaron el concepto para convertirse en una disciplina académica. No obstante, no ha habido muchas obras que colocaran con éxito el espíritu empresarial en el centro de las ciencias económicas (Baumol, 1968; Landstrom, 2010). En la actualidad, la investigación empresarial ha seguido demostrando que las actividades empresariales desempeñan un papel importante en la creación empleos y reducción de la pobreza, por lo que es vital para crear una economía fuerte (Brush et al., 2009; Bruton et al., 2013; Kiss et al., 2012) mientras se explora a sí misma más profundamente como una disciplina académica (McDonald et al., 2015; Suddaby et al., 2015)."

Esta entrada fue publicada en Empresarialidad y etiquetada entrepreneur, Escuela Austriaca por Martin Krause. Guarda enlace permanente [https://bazar.ufm.edu lacademicos-vietnamitas-analizan-desarrollo-la-teoria-la-empresarialidad-destacandolas-contribuciones-austriacas/] .

UN PENSAMIENTO EN “ACADÉMICOS VIETNAMITAS ANALIZAN EL DESARROLLO DE LA TEORÍA DE LA EMPRESARIALIDAD DESTACANDO LAS CONTRIBUCIONES «AUSTRIACAS»"

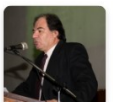

Jorge Sánchez

en 6 enero, 2020 en 6:49 pm dijo:

Ciertamente, mientras el enfoque neoclásico prioriza el equilibrio y supone conocimiento perfecto asignando un rol más bien maximizador y estático al decisor; el enfoque austríaco supone el proceso de mercado dinámico y signado por conocimiento imperfecto que suele asociar oportunidades al decisor vigilante de datos del propio mercado que aprovecha para generar beneficios contratando talento y recursos para explotarlo mientras el conocimiento le procura ventaja. Los ecosistemas empresarios pueden ser comprendidos relacionando instituciones y procesos de mercado que los determinan. El programa de investigación de la Escuela Austríaca puede contribuir de manera determinante adicionando temas por el estilo. Muchas gracias. 


\section{References}

Krause, M. (2020). Académicos vietnamitas analizan el desarrollo de la teoría de la empresarialidad destacando las contribuciones "austriacas". El foro y el bazar (Universidad Francisco Marroquín). Retrieved from: https://bazar.ufm.edu/academicos-vietnamitas-analizandesarrollo-la-teoria-la-empresarialidad-destacando-las-contribuciones-austriacas/

Vuong, Q. H., La, V. P., Vuong, T. T., Nguyen, H. K. T., Ho, M. T., \& Ho, M. T. (2020). What have Vietnamese scholars learned from researching entrepreneurship? A systematic review. Heliyon, 6(4), e03808. 